\title{
Research on the regional public brand of agricultural products based on block chain technology-Exploration of digital economy innovation
}

\author{
Weiwei Meng ${ }^{1, *}$ \\ ${ }^{1}$ Business department, Shandong Polytechnic College, Jining, Shandong, China
}

\begin{abstract}
Structural oversupply pushes fresh agricultural products to the buyer's market, and the market's demand for regional public brands of agricultural products is increasing day by day. Based on block chain technology, this paper analyzes the countermeasures for the construction of regional public brand of agricultural products, which is also an effective measure to promote digital economy innovation and accelerate the promotion of digital industrialization..
\end{abstract}

\section{Literature review and questions raised:}

As the attention of blockchain technology continues to increase, some scholars at home and abroad have proposed to build "blockchain +" technology to reform the agricultural field. Such as Linbo He proposed build nests market as template block chain + technology "small farmers" production mode and mechanism for poverty alleviation, represented by Qiqi Liu etc technology based on block chain of agricultural products quality traceability system builds, with Lina $\mathrm{Yu}$ as the representative of modern agricultural products supply chain based on block chain, represented by Sun Jianming etc under the block chain technology point of view of rural electricity of peasant household credit evaluation research. Although the above literature has pointed out the direction for the combination of block chain technology with the development of domestic agriculture, no digital economy innovation exploration has been made for the construction and e-commerce operation of regional public brands of agricultural products in agriculture.

\section{Regional public brands of agricultural products:}

\subsection{Development status of regional public brands of agricultural products:}

The regional public brand of agricultural products is the product of the development and change of an era. It not only represents a certain quality of products, but also has a certain brand story and brand value, with its own communication influence. Generally speaking, regional public brand of agricultural products refers to the agricultural products brand owned by relevant organizations and used jointly by several agricultural producers and operators in a region with specific natural ecological environment, historical and cultural factors ${ }^{[1]}$. This kind of brand consists of "place of origin + product name". In principle, the place of origin should be at the county or prefectural level, and the scope of production area should be clear.

\subsection{Problems in the development of regional public brands of agricultural products}

Throughout the development of regional public brands in different regions, there are several common problems as follows:

\subsubsection{The brand benefit is not well highlighted.}

Brand awareness, but not brand value; Some brand registration is only to meet the local agricultural products address mark brand "quantity" improvement, and ignore the "quality" of the construction and sustainable development, and the lack of national well-known brand phenomenon contradiction; Some brands even have less local presence.

\subsubsection{The phenomenon of "free riding" is serious.}

Agricultural products are mainly spread by word of mouth, the market is uneven, the product quality is unstable, the traceability system is not perfect, and the abuse of brands seriously affects consumers' decisionmaking and consumption experience. The essence of the problem is the lack of unified industry standards and supply chain system, professional skills and personnel.

\footnotetext{
* Corresponding author: ula sd@163.com
} 
2.2.3 There is no special team responsible for brand cultivation, and it should be carried out to the end.

The cultivation of regional public brands of agricultural products is a long process of precipitation. Some governments hold press conferences and other forms of publicity in the early stage of brand construction, but in the later stage, there is a lack of a stable subject for longterm publicity and promotion. The essence of the problem is that the local government does not attach enough importance to the brand, and the planning, financial support and policy guarantee are not in place.

2.2.4 Some farmers and specialized farmer cooperatives have weak brand awareness and only pay attention to sales volume rather than quality building, which leads to slow brand development.

\subsection{The significance of building regional public brand of agricultural products}

\subsubsection{Enhancing regional influence can promote the integrated development of local secondary and tertiary industries.}

We will enable farmers not only to benefit from improving the quality and efficiency of agriculture, but also to share in the profits from the value-added gains of the development of secondary and tertiary industries.

2.3.2 For producers and processors, the added value of agricultural products can be enhanced, economic benefits can be improved, and industrial foundation can be consolidated, so as to further improve agricultural quality, benefits and competitiveness and enhance the vitality of rural development.

\subsubsection{For the industry, the branding development of agricultural products is conducive to accelerating the process of agricultural modernization, realizing the structural reform of the agricultural supply side and promoting the overall development of agriculture.}

\subsection{Methods for building regional public brands of agricultural products}

\subsubsection{Government supervision, industry leadership and enterprise execution.}

Enterprises determine the local leading enterprises as the main body of cultivation, timely brand registration, to build the enterprise brand in the regional public brand. The cultivation of regional public brands needs the concerted efforts of local governments, industry associations and enterprises. The specific division of labor is as follows: the government shall formulate relevant management norms and procedures, and formulate relevant emergency defence and protection measures according to the vulnerability characteristics of the agricultural products industry. The government authorizes the only enterprise to build the enterprise brand in the regional public brand, and breaks the problem of "free riding" of public brands. Industry associations formulate product standards, that is, to achieve standardization of product quality, product packaging, product appearance, product after-sales service standardization. The government strictly supervises the tracking of product quality, operation and effect in accordance with standards, and builds a traceability system for agricultural products with the help of blockchain technology.

\subsubsection{Strengthen brand publicity and establish multi-dimensional promotion channels.}

Based on the Internet, enterprises upgrade and transform the production, circulation and sales process of commodities through the use of big data, artificial intelligence and other advanced technological means, so as to reshape the business structure and ecosystem, and deeply integrate online services, offline experience and modern logistics into a new retail mode ${ }^{[2]}$. Create a professional brand operation team, design the media matrix covering the whole network to carry out new media marketing and operation. Relevant content creation and release of short videos, public accounts, microblogs, etc., using live broadcast platform with goods platform, with the help of community group buying and traditional e-commerce platform for promotions. Data crawler technology is used to collect online user data, and block chain technology is used to capture offline store user entry path and interactive behavior data before the shelf. In this way, user labels can be formed, user portraits can be drawn with data tools, and user portraits can be optimized and brand operation strategies can be adjusted.

\subsubsection{Strengthen the cultivation and agricultural scientific support for emerging professional farmers.}

Increasing the vocational education of farmers is the most effective way to promote the growth and expansion of new farmers. We will vigorously develop and expand the local science and technology service team, so as to improve the scientific and technological support in production and sales while popularizing farmers' knowledge. At the same time, we can make use of the block chain technology to timely track and feedback the effect on farmers.

2.4.4 Strengthen the integrated development of agriculture and local secondary and tertiary industries to drive the tertiary and secondary industries in small towns and central villages.

Industry development, prosperity of urban economy. Promote the development of local tourism by developing 
rural tourism and supporting services, such as agricultural sightseeing areas, characteristic towns, characteristic ecological experience tours, and related cultural and creative products. The project development combined with block chain technology, with the help of modern industrial technology and modern agricultural equipment to improve production efficiency, to create a modern agricultural production system with high yield, high quality and low consumption, in order to force the development of the secondary industry.

\section{Blockchain technology}

\subsection{Concept and characteristics of blockchain technology}

Blockchain technology has its origins in $\operatorname{Bitcoin}^{[3]}$.Is the underlying technology at the core of many digital currency schemes represented by Bitcoin, and was originally designed to address the over-reliance on trusted third parties in electronic payments. Blockchain combines hash functions, Merkl trees, and Proof of Work (Pow). ${ }^{[4]}$ It combines public key encryption, digital signature, zero knowledge proof and other cryptography technologies, and becomes a new distributed infrastructure and computing paradigm ${ }^{[5]}$.As for the concept of blockchain technology, it is often quoted that "public ledger" is established on the Internet, and all users jointly "keep accounts" and "check accounts" on the ledger to ensure the authenticity and immutability of information ${ }^{[5]}$. Blockchain technology, with its characteristics of decentralization, immutability, trust mechanism and programmable, has been applied in government affairs, finance and digital currency. Some experts and scholars have proposed the concept of "Blockchain +". In the future, Blockchain technology will be promoted and applied in various industries.

\subsection{Blockchain has the following four characteristics:}

\subsubsection{First, decentralization.}

The most obvious advantage of blockchain technology is decentralization.In 2008, Satoshi Nakamoto proposed the design of bitcoin is derived from this technology, get rid of such as banks and other third party as the center of the registration certification and review. Bitcoin is also one of the more successful application scenarios of blockchain technology. Its current advantage is to improve the efficiency of transaction and reduce the transaction cost.

\subsubsection{The second, immutability.}

Based on the timestamp technology, this technology can realize the permanent storage of information in the chain and establish an unforgeable database. If any node information is modified, the hash becomes invalid. This is difficult to do in practice if you modify all the node information.

\subsubsection{Third, trust mechanism.}

There is no need for trust between transaction subjects, that is, the trustable system under blockchain technology is based on mathematical algorithms. Any node in the blockchain can act as both the subject of the activity and the supervisor of the activity, thus reducing the risk or cost of mutual trust.

\subsubsection{The fourth, programmability.}

Over time, blocks can be extended and used on top of the underlying open source infrastructure. The use of smart contracts in finance underlines the value of blockchain technology. Programmability allows flexibility in the use of smart contracts, as contract terms can be added according to different needs. At present, this trend is being applied to various industries in the society.

\section{Application exploration of block chain technology in regional public brand construction and e-commerce operation of agricultural products}

\subsection{Establish an information traceability system for regional public brands of agricultural products by taking advantage of the decentralization and immutability of block chain technology.}

This system needs the government, industry and enterprises, to abandon the traditional electricity trading environment, the traditional electric business platform as the center of the trading system, but each subject in each link of information added to the block chain of each node, and only can increase the information, do not cut or tampered with, to ensure the safety of the information and traceability. For example, in the upstream of the supply chain of regional public brands of agricultural products, electronic tag technology can be used to audit the information of agricultural products and farmers to ensure the absolute geographical attributes of regional brands of agricultural products. In the production of agricultural products, a series of Internet of Things technologies can be used to complete and true record all information of agricultural products; In the links of quality inspection, processing and packaging of agricultural products, electronic tag technology is used to track and record. In the links of mid-stream transportation and wholesale, private keys are used to store them in the blockchain. In the downstream retail link, the regional public brand information of agricultural products can be fully presented through twodimensional code. 


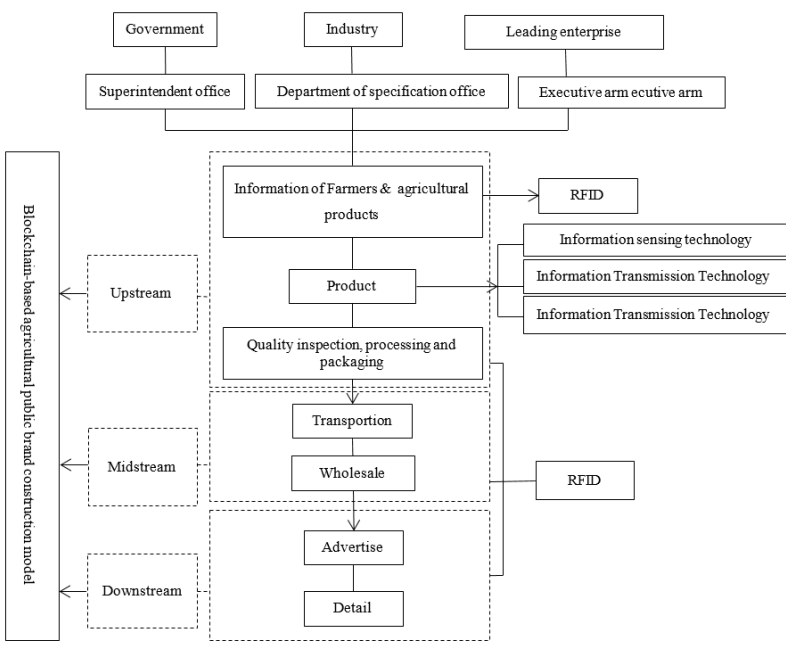

Figure 1: Information traceability system of regional public brands of agricultural products based on block chain

\subsection{Utilizing the decentralization and programmability of blockchain technology to establish a financial service system for regional public brands of agricultural products.}

The main performance for the construction of payment and insurance, financing system. In the traditional ecommerce transaction process, the third party represented by the bank is not absolutely safe. In the blockchain technology, the third-center transaction mode should be abandoned, and all nodes should accept open links and receive data exchange freely and fairly. In addition, the programmable smart contract technology ensures the information transmission between the buyer and the seller, and at the same time, it also backups the nodes in other links to ensure the security of the payment system. The establishment of intelligent contracts based on blockchain technology can help the transaction subject to deal with insurance claims quickly and easily. In addition, the intelligent contract automatic processing function can also be used to solve the micro-financing risks such as usury that may be faced between transaction subjects, as well as the complex financing procedures. These three aspects can jointly improve the speed and safety of capital turnover and ensure the fund guarantee in the process of building regional public brand of agricultural products.

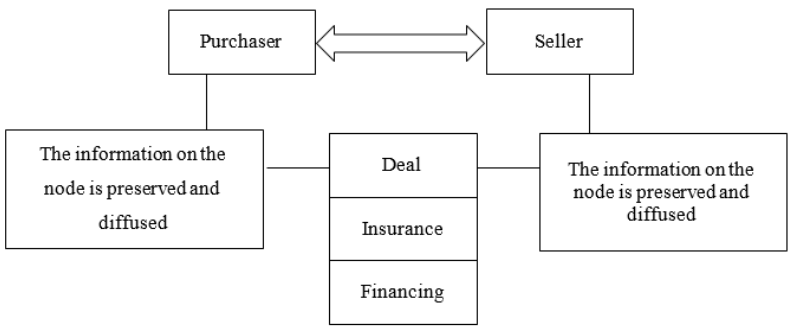

Figure 2: Financial service system of public brands in agricultural products region

\subsection{Utilizing the programmability and decentralization of blockchain technology to establish a regional public brand agricultural science service system.}

Block chain can continue all agricultural intensive data in storage area, agricultural science and service personnel can give accurate support, through the data block chain technology at the same time can cultivate consumers in the intimate relationship between growers, improving consumer experience, to help the seller make precise marketing plan, strengthen the brand publicity, expand marketing channels, in order to form stable closed-loop market. The collection, processing and application of decentralized information at each node can improve the level of agricultural modernization and further promote the sustainable development of regional public brands.

\section{Conclusion}

To sum up, this paper analyzes the current problems encountered in the construction and operation of regional public brands of agricultural products, and applies the blockchain technology to this field to accurately judge the new demands of the digital market and support the development of new business forms of the digital economy.

\section{References}

1. Notice on the Collection of Regional Public Brands of Agricultural Products in China Agricultural Brands Catalogue 2019.Ministry of Agriculture and Rural Affairs official website (2019)

2. Du Ruiyun. Jiang Kan. New retail: connotation, development motivation and key issues [J]. Price Theory \& Practice (2017)

3. Nakamoto S. Bitcoin: a peer-to-peer electronic cash system [Online], available: https://bitcoin.org/bitcoin.pdf, October 5 (2018)

4. Dwork C, Naor M. Pricing via processing or combatting junk mail. In: Proceedings of the 12th International Cryptology Conference. California, USA: Crypto (1992)

5. Yuan Y, Wang FEI-YUE. Blockchain: The state of the art and future trends. Automatica SINICA, 2016, 42(4): 481-494.Progress and prospects of blockchain technology. Acta Automatica Sinica (2016) 